\title{
The blooming of a hobby: a history of natural history
}

\section{Alwyne Wheeler}

The Heyday of Natural History. By Lynn Barber. Pp.320. (Cape/Doubleday: 1980.) $£ 9.50, \$ 17.95$.

THE middle years of the nineteenth century saw a striking flowering of popular interest in natural history in Britain. The economic and social conditions of the time had produced an increase in the number of literate people who had more leisure and were thus able to utilize their time in what was clearly a health-giving, mindimproving hobby - both worthy objectives in the moral climate of the period. In addition, developments in printing, for example stereotyping and electrotyping, permitted a great increase in the number of popular books, often illustrated with colour plates at relatively low prices.

The result was an extraordinary burgeoning of the literature of natural history written for a popular market. The availability of such books stimulated the interest of even more middle-class naturalists, to result in a cycle of demand and supply which saw the nineteenth century out. The consequences of this great increase in popular natural history and its literature have had considerable influence in our time, for it was during the midnineteenth century that many local natural history societies were founded (and those that came later were started by people raised during the period). Many such societies started local natural history museums, and even now have their own publications and libraries, and thus still exert a considerable influence on natural history in Britain although, responding to pressures on the environment today, much of the amateur naturalist's efforts go in supporting conservation-orientated societies.

In this view I differ from the conclusion of Lynn Barber that from the 1870s, in the aftermath of the revolution in thought following the acceptance of Darwin's theories, natural history became "dull". The later years of the nineteenth century simply saw a dichotomy between amateur naturalists and professionals, the latter having been few in number before the 1870s. The amateur interest in natural history has continued as strongly as ever, but the professional naturalists have become more specialized in their fields and in their writings, and few have possessed the breadth of knowledge, the ability or the bravery to produce popular writing comparable to that which flourished in the Victorian period.

Lynn Barber's book is a most readable account of the great years of the Victorian naturalists (Victorian being loosely applied). The story is a good one, some

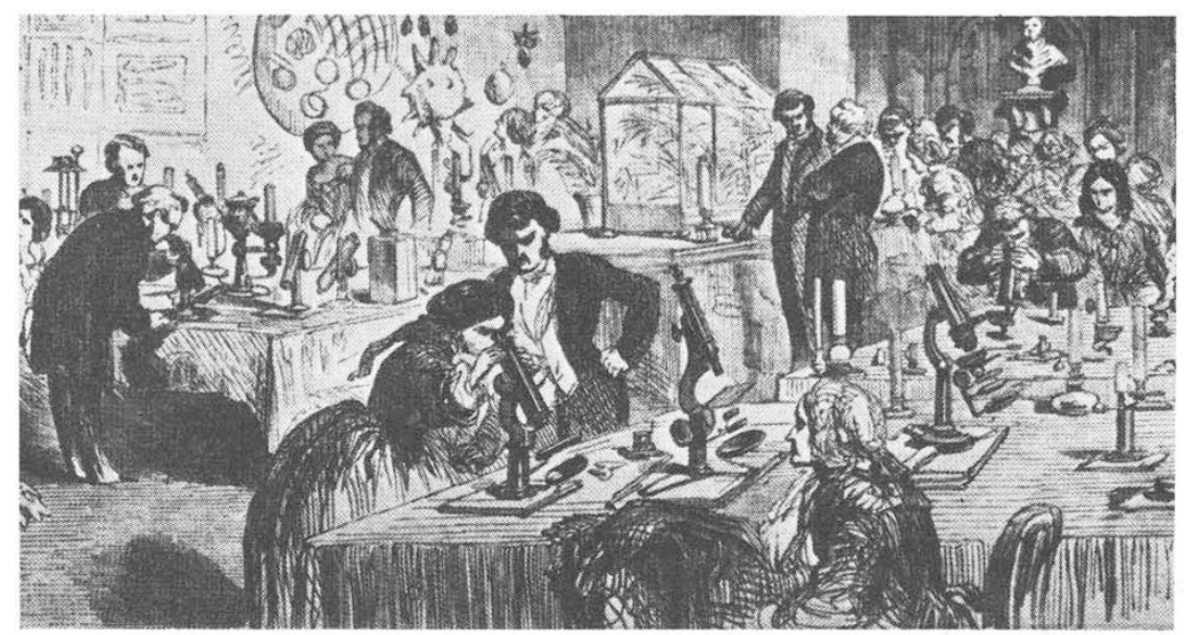

“'Scientific Conversatzione at Apothecaries' Hall”, from the Illustrated London News, 1855

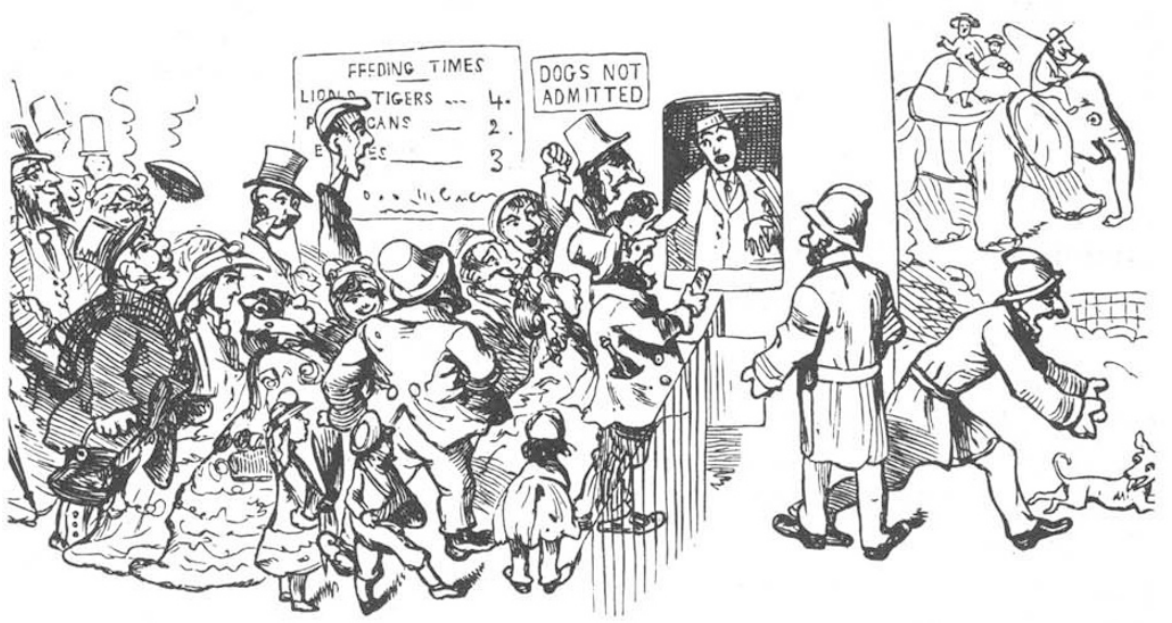

“Holiday Time at the Zoo”, 1872

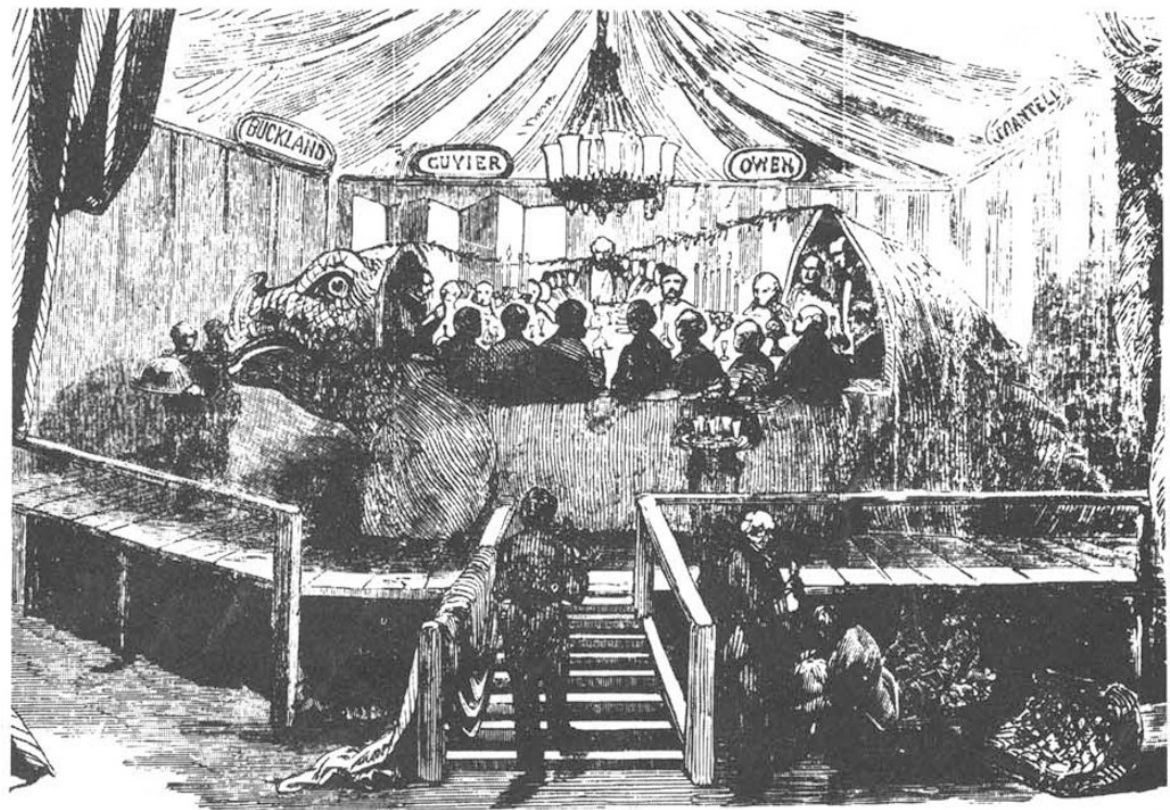

The Iguanodon dinner, 1854 


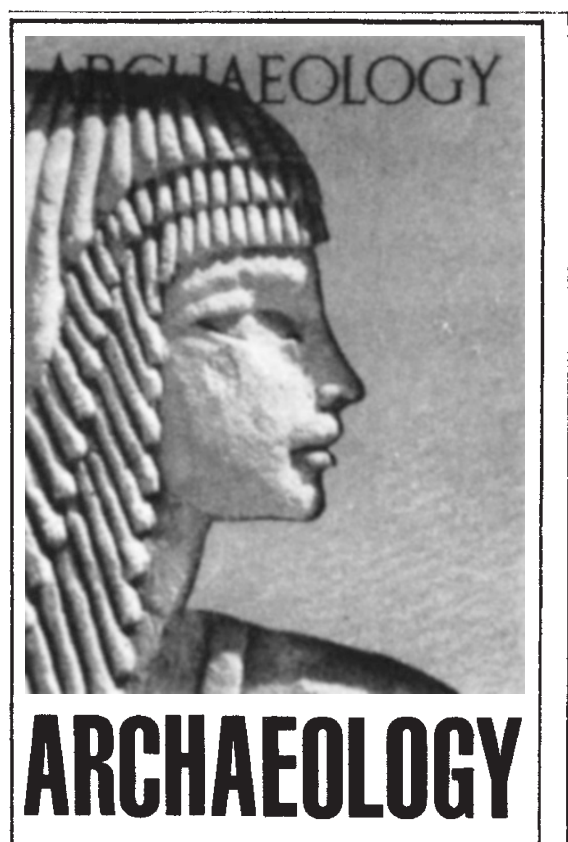

\section{The Magazine for Past Lovers}

Admit it - you've always been secretly fascinated by the mysteries of antiquity... always wondered what life was really like in ancient Egypt, China, Greece, Mexico, Peru. Find out in ARCHAEOLOGY Magazine! Six times a year its authoritative clearly-written articles and stunning color photographs bring the ancient world alive. Meet the peoples of the past. Marvel at their achievements, and admire the beauty they left behind. There's nothing else like ARCHAEOLOGY. Try it now.

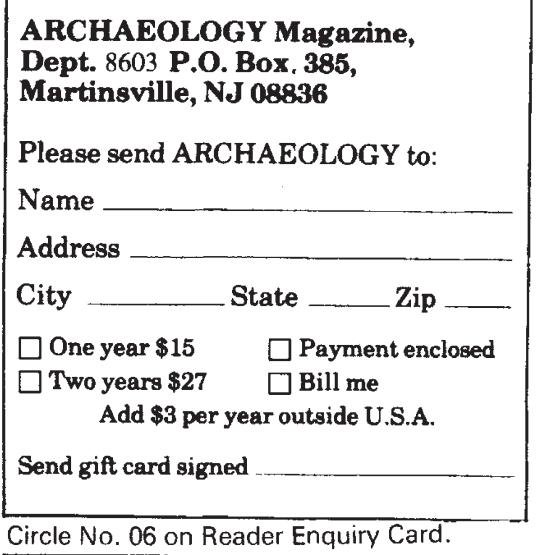

superbly interesting characters appear and the material is handled in a masterly fashion.

The first section recounts the social and historical backgrounds, the second contains accounts of Linnaeus, Cuvier, Audubon, Rafinesque, Swainson and Charles Kingsley. Later sections feature Waterton, Gosse, Ward, Mary Anning, the Bucklands, Owen, Sedgewick, Murchison, Huxley and Darwin. But the treatment is not merely biographical; rather, the work and the influence of these "giants" of the nineteenth century is skilfully woven into an account of the development of British natural history, although biographical details have been included to set them in their background. In working this complicated tapestry into an attractively presented, enjoyable and well-written story Lynn Barber deserves all credit.

No doubt it is because of her background as an experienced journalist and broadcaster that her book is presented with such panache. This background may, however, have led her to include some "human interest" stories which are generally now discredited amongst historians of natural history. Thus, the loss of labels from Cuming's mollusc shell collection due to Mrs Gray's carelessness is now dismissed as a canard. Nor was the unfortunate A.W.E. O'Shaughnessy's appointment in the British Museum to work on insects due solely to the influence of his patron as is inferred here; he was simply transferred from one department within the Museum to another, having passed a test of his knowledge of zoology which the other contender had failed.

One has to say that most of the sources used by Miss Barber are secondary. I doubt whether one can rely overmuch on Kingsley's view of Victorian natural history, or on William Swainson and especially not on Audubon for objective

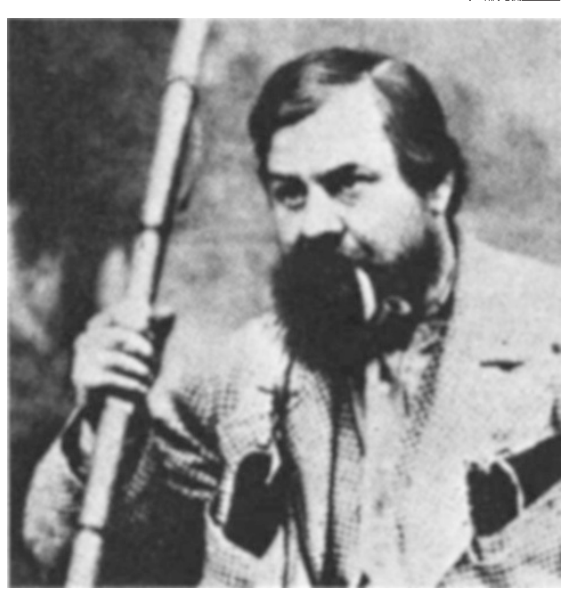

Frank Buckland, naturalist extraordinary

views of their contemporaries. They were all too involved in the period themselves, and Swainson and Audubon certainly had axes of various kinds to grind. The reliance on secondary sources tends to affect the overall images in the book, and also possibly accounts for some of the more alarming generalizations and particular errors. Surely it is not true that between Cuvier's Le Règne Animal of 1817 and Darwin's Origin of Species in 1859 “'almost no major breakthroughs were made'? Two discoveries alone, that of Schwann (1839) of animal cells, and that of the mammalian ovum by von Baer (1827), would today be given the accolade of "breakthroughs",

For these and other reasons Lynn Barber's book cannot be credited as an original history of natural history, but as a readable and well-produced introduction to the subject it is unsurpassed.

Alwyne Wheeler is editor of the Archives of Natural History (formerly the Journal of the Society for the Bibliography of Natural History) and works at the British Museum (Natural History).

\section{The "why" of animal culture}

\section{W.C. McGrew}

The Evolution of Culture in Animals. By John Tyler Bonner. Pp.216. (Princeton University Press: 1980 .) $£ 8.10, \$ 14.50$.

A Distinguished cell biologist, J.T. Bonner, has written an ambitious book on the behaviour of animals. In it, he tackles the question of culture as a direct product of the evolutionary processes of natural selection: "[Culture] . . . is as biological as any other function of the organism, for instance, respiration or locomotion". In addressing social scientists, Bonner does not shrink from the implications of this position for human culture and confronts the issues in his opening chapter. From the beginning it is a pleasure to find a book so lucidly written and so free of jargon.

The author's ultimate goal is to explain why we (humans) have culture at all. To appreciate its adaptive significance requires a step-wise reconstruction of its phylogeny, and it is to this task that much of the book is directed. Bonner starts at the most basic levels of evolutionary mechanisms and advances on a broad front. His definitions are as comprehensive as possible; culture is defined as ". . . the transfer of information by behavioural means, most particularly by the process of teaching and learning'. (Such a definition is not without faults, for instance it gives no inkling of the cumulative nature of the phenomenon). The author compares the genome and the brain as informationprocessing structures, with genes and "memes", respectively, as the units of information transmission - here, and elsewhere in the book, he calls upon Dawkins's The Selfish Gene. The latter 